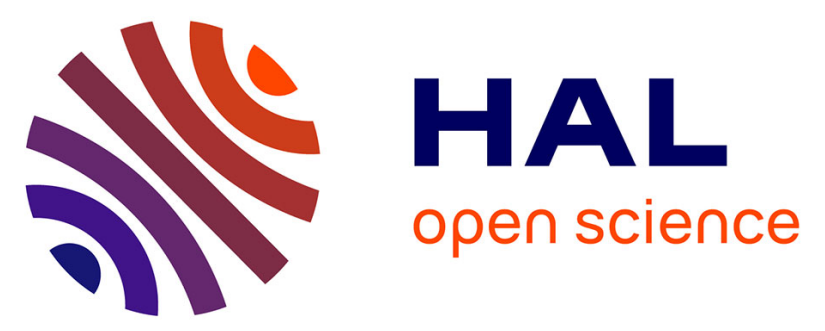

\title{
Investigating biochemical processes to assess deadwood decay of beech and silver fir in Mediterranean mountain forests
}

\author{
F. Lombardi, P. Cherubini, R. Tognetti, C. Cocozza, B. Lasserre, Mario \\ Marchetti
}

\section{To cite this version:}

F. Lombardi, P. Cherubini, R. Tognetti, C. Cocozza, B. Lasserre, et al.. Investigating biochemical processes to assess deadwood decay of beech and silver fir in Mediterranean mountain forests. Annals of Forest Science, 2012, 70 (1), pp.101-111. 10.1007/s13595-012-0230-3 . hal-01201451

\section{HAL Id: hal-01201451 \\ https://hal.science/hal-01201451}

Submitted on 17 Sep 2015

HAL is a multi-disciplinary open access archive for the deposit and dissemination of scientific research documents, whether they are published or not. The documents may come from teaching and research institutions in France or abroad, or from public or private research centers.
L'archive ouverte pluridisciplinaire HAL, est destinée au dépôt et à la diffusion de documents scientifiques de niveau recherche, publiés ou non, émanant des établissements d'enseignement et de recherche français ou étrangers, des laboratoires publics ou privés. 


\title{
Investigating biochemical processes to assess deadwood decay of beech and silver fir in Mediterranean mountain forests
}

\author{
F. Lombardi • P. Cherubini $\cdot$ R. Tognetti $\cdot$ C. Cocozza • \\ B. Lasserre • M. Marchetti
}

Received: 28 November 2011 / Accepted: 27 July 2012 /Published online: 21 September 2012

(C) INRA / Springer-Verlag France 2012

\begin{abstract}
- Context We investigated the relationships between decay classes, morphological characteristics and chemical compounds in Abies alba Mill. and Fagus sylvatica L. stumps in two forest stands in the central Apennines (Italy). The analysis of deadwood decomposition is important in estimating carbon sequestration potential and carbon residence time in forest ecosystems. In addition, deadwood decomposition affects nutrient cycling and microhabitat distribution.
\end{abstract}

\section{Handling Editor: Barry Alan Gardiner}

Contribution of co-authors Lombardi F., Tognetti R. and Marchetti M. designed research.

Lombardi F., Lasserre B. and Cocozza C. performed research.

Lombardi F., Lasserre B., Tognetti R. and Cherubini P. analyzed data. Lombardi F. and Tognetti R. wrote the paper.

F. Lombardi $(\bowtie) \cdot$ R. Tognetti $\cdot$ C. Cocozza $\cdot$ B. Lasserre $\cdot$

M. Marchetti

Dipartimento di Bioscienze e Territorio, Laboratorio EcoGeoFor,

Università degli Studi del Molise,

Contrada Fonte Lappone,

86090 Pesche, IS, Italy

e-mail: fabio.lombardi@unimol.it

R. Tognetti

e-mail: tognetti@unimol.it

C. Cocozza

e-mail: claudia.cocozza@unimol.it

B. Lasserre

e-mail: lasserre@unimol.it

M. Marchetti

e-mail: marchettimarco@unimol.it

P. Cherubini

Landscape Dynamics Unit-Dendroecology,

WSL Swiss Federal Research Institute of Forest,

Snow and Landscape,

8903 Birmensdorf, Switzerland

e-mail: paolo.cherubini@wsl.ch
- Aims The overall aim of this study was to investigate the decomposition processes in a mountainous Mediterranean ecosystem, and specifically to assess changes in chemical variables (lignin, cellulose, carbon and nitrogen content) in deadwood during the decomposition process, in relation to decay classes and to the species.

- Methods Cross-sections were collected from stumps. Samples were assigned to visually discernible decay classes, and cellulose, lignin and carbon (C) and nitrogen (N) content in relation to total dry mass were analysed during the decay process.

- Results Results showed how $\mathrm{C} / \mathrm{N}$ ratio decreased over decades due to an increase in nitrogen content. On the contrary, carbon concentration in stumps remained substantially stable. Lignin degraded slowly in comparison with cellulose and differences between species were observed.

- Conclusion The hypothesis that the conifer species would decompose faster than deciduous species did not prove correct. The slower decay of lignin compared to cellulose suggested that lignin could be an important long-term source of soil organic carbon, and that this process could be greatly affected by forest species mixtures. Finally, decomposition processes in the investigated montane-Mediterranean forests were definitely faster than in the colder climates of northern Europe.

Keywords Deadwood - Apennines · Decay progression . Carbon-nitrogen $\cdot$ Lignin-cellulose

\section{Introduction}

Deadwood is a key component in forest ecosystems, and is important for understanding the global carbon cycle and for maintaining biodiversity (Lassauce et al. 2011). Nevertheless, until the 1980 s, only a few pathologists were interested in wood-decay processes and studying the spatio-temporal 
distribution of deadwood in forest ecosystems. More recently, increasing attention has been given to the assessment of the quantity of deadwood lying on the floor of forests and nutrient dynamics (Laiho and Prescott 2004; Muller-Using and Bartsch 2009; Saunders et al. 2011).

Deadwood may act as a sink for atmospheric carbon and it is an important structural and functional component of forest ecosystems (Harmon et al. 1986). Indeed, deadwood influences soil development, stores carbon, nutrients and water, reduces erosion and serves as a major habitat for saproxylics (Lassauce et al. 2011). Nevertheless, in temperate and Mediterranean Europe, studies on the quantity of deadwood have been sporadic and deadwood is poorly described in comparison to other systems (Bretz Guby and Dobbertin 1996; Lombardi et al. 2010; Olajuyigbe et al. 2011). Moreover, the contribution of deadwood to nutrient cycling, soil carbon and nutrient pools and to long-term forest sustainability is not well understood.

Nowadays, the increasing attention to deadwood function and decomposition makes the management and utilization of deadwood in forest a primary objective, providing a chance to integrate many related research subjects. This involves comprehensive, long-term and multi-scale research, which focus on several aspects: (a) the simulation and quantification of decomposition processes and decomposition rates; (b) the modelling of biochemistry cycling and nutrients released during deadwood decomposition; (c) the change of soil physical and chemical properties and microbe communities during deadwood decomposition; (d) the long-term response, adaptation and feedback of deadwood decomposition through carbon dioxide fluxes and global change and (e) the relationship between deadwood decomposition and ecological process integrity and forest health (Zhou et al. 2007).

The decomposition of deadwood has been investigated in tropical and subtropical forests of Central America (Wilcke et al. 2005) and Australia (Mackensen and Bauhus 2003), and in boreal forests of Northern Europe (Aakala 2010). The majority of studies on deadwood decay dynamics, however, have been carried out in the coniferous forests of North America (Lambert et al. 1980) or Northern Europe (Krankina et al. 1999). In fact, information about deadwood abundance, spatial and temporal development is relatively abundant in the American North-Western Pacific ecosystems, for which pivotal studies provided basic knowledge for the sustainable management of forest ecosystems (Harmon et al. 1986; Lambert et al. 1980). In particular, forest inventory surveys have been recently focused on issues related to carbon sequestration (e.g. Richards and Stokes 2004), aiming at assessing the spatial distribution of deadwood and estimating species-specific carbon sequestration rates. In these studies, it soon became clear that the temporal dynamics of deadwood decay are still poorly understood.
In an early attempt to determine decay rates for Southern European forests, Lombardi et al. (2008) applied methods commonly used in North America, focusing on dendrochronological techniques. They found that time-since-naturaldeath of silver fir and beech stumps in Central Italy only roughly indicates decay rates because decay processes only fully start when the tree falls to the forest floor and not the year of tree death, which can be assessed by dendrochronological methods. It was noticed that the typical morphological analysis carried out in the field (Hunter 1990) is insufficient to describe the wood decay progression in these forest ecosystems. As proposed by several authors (Bütler et al. 2007; Saunders et al. 2011) wood density, carbon, nitrogen and phosphorous contents, and lignin and cellulose concentrations may be used to better assess decay patterns of coarse woody debris correlated with specific site characteristics, such as soil and air microclimatic conditions.

Lombardi et al. (2008) demonstrated that time since death and decay class were inconsistently related and the structural characteristics of logs did not always reflect the length of time they had been dead (see also Daniels et al. 1997). Stumps could also derive from living trees that started to decay in the heartwood many years before the overall tree death (Cherubini et al. 2002). On the other hand, the features of a stump could erroneously indicate advanced stages of decay, and mask recent tree death. However, decay classes described in the field through visual assessment reflect the decay progression of wood and the sequence of organisms that decompose the wood on the forest floor rather clearly. Questions remain on deadwood behaviour as chemical pool within forest ecosystems. This is particularly interesting in forest systems where a large mass of deadwood is created by short-term events. Such episodic situations are common following fires, pest outbreaks, windstorms or logging where stumps constitute a large mass of wood (Lambert et al. 1980).

An improved knowledge of the decay progression of deadwood and the factors affecting these changes is important for maintaining long-term sustainability of soils, to help conservation, and to evaluate the role of deadwood in carbon storage and to preserve microhabitat occurrence. The overall aim of this study was to investigate the decomposition processes in silver fir and beech forests in a mountainous Mediterranean ecosystem, and specifically to assess changes in chemical compounds (lignin, cellulose, carbon and nitrogen content) in deadwood during the decomposition in relation to decay classes. It was hypothesized that the coniferous silver fir would decompose at a faster rate than the deciduous beech, due to different proportion of chemicals such as lignin and cellulose, resulting in a different chemical variability depending on decomposition classes and wood types. In particular, we expected that the faster decay in silver fir could be induced by lower lignin content. Typically, the classifications of deadwood decomposition processes are inherently subjective, raising 
questions about repeatability. Such questions are of particular concern because in practice, the class definitions themselves often fail to clarify how to assign deadwood that is decomposing to a specific decay class. A dendroecological approach, which includes chemical analysis of wood, is proposed to avoid some of the problems related to the use of decay classification for estimation of the mass of woody debris.

\section{Materials and methods}

\subsection{Site description}

This study is located in two mountain sites in the Apennines (Molise Region, Italy). The two sites, considered representative of montane beech and coniferous forests of the Mediterranean, are located $10 \mathrm{~km}$ apart from each other and both are within the temperate bioclimatic region, humid-meso-temperate type. Characteristics of the study sites are shown in Table 1.

The silver fir site is located in the forest "Abeti Soprani", near Pescopennataro (Isernia). The study area is located at an elevation ranging from 1,000 to 1,450 ma.s.l. The slope is north facing, and the geology is dominated by Miocenic-clay soils and Cretacic white limestone. Rendzina soils are common. The mean annual temperature at the nearest meteorological station (Capracotta) is $8.4{ }^{\circ} \mathrm{C}$, with an annual mean precipitation of 1,124 mm (1927-1987). January is the coldest month and July is the warmest month, with mean temperatures of -0.1 and $18.0^{\circ} \mathrm{C}$, respectively. The forest is a relict stand dominated by silver fir, typical of the fir forests currently widespread in the Mediterranean and Anatolian regions. Its structure and composition are similar to forests common in the past throughout the Apennines, but which nowadays survive only in small areas of the Italian peninsula.

The European beech site is located in the "Montedimezzo" MaB UNESCO Reserve, close to Vastogirardi (Isernia). This forest stand has been unmanaged since 1950. The site is located at an elevation ranging from 920 to 1,240 ma.s.l. The slope is north facing, and the geology is dominated by

Table 1 Main characteristics of the study sites

\begin{tabular}{lll}
\hline & $\begin{array}{l}\text { Abeti Soprani } \\
\text { (silver fir) }\end{array}$ & $\begin{array}{l}\text { Montedimezzo } \\
\text { (beech) }\end{array}$ \\
\hline Latitude (degrees) & $41^{\circ} 51^{\prime} 51^{\prime \prime}$ & $41^{\circ} 45^{\prime} 16^{\prime \prime}$ \\
Longitude (degrees) & $1^{\circ} 17^{\prime} 54^{\prime \prime}$ & $14^{\circ} 16^{\prime} 05^{\prime \prime}$ \\
Altitude (m a.s.1.) & 1,260 & 1,100 \\
Aspect & North & North \\
Slope (degrees) & $10-15^{\circ}$ & $10^{\circ}$ \\
Annual T ${ }^{\circ} \mathrm{C}$ mean & 8.4 & 8.6 \\
Annual pp mean $(\mathrm{mm})$ & 1,124 & 1,022 \\
\hline
\end{tabular}

Cretacic limestone, with greensands and clay soils prevalent. The mean annual temperature at the nearby meteorological station (Vastogirardi) is $8.6^{\circ} \mathrm{C}$, with an annual mean precipitation of $1,022 \mathrm{~mm}(1980-1991)$. January is the coldest month and July the warmest month, with average temperatures of 1.5 and $17.0^{\circ} \mathrm{C}$, respectively. The structure of this Apennine-Corsican montane beech forest is very diverse, containing all phases of the forest life cycle.

\subsection{Sampling protocol}

Cross-sections of beech and silver fir were taken from stumps of trees that had died naturally.

Stumps were considered as the part of a tree trunk left protruding from the ground after the tree has naturally fallen as consequence of storms or insects attacks. In total, 50 silver fir and 59 beech cross-sections from stumps were sampled, always taken approximately at a height of $40 \mathrm{~cm}$. Ten crosssections for each decay class were sampled for the two species, with the exception of beech stumps in decay classes 1 and 2: in these cases, 14 and 15 sections were respectively collected. For each stump, the diameter at the top was measured. Considering that deadwood composition and shape are strongly influenced by many factors that affect decay rates, such as slope aspect and soil moisture and log diameter, each site was chosen taking into account the common requirements for a regular slope and comparable soil characteristics. The study sites were identified measuring the slope and aspect values (degrees) with several replications for each site. Moreover, attention was dedicated to select the stumps to be sampled: the micro-topography where each stump was located was observed, avoiding sampling stumps located in impluvium and watershed areas. Stumps were selected only if their height from the forest floor was below $40 \mathrm{~cm}$, and if diameters at the top level ranged from 30 to $50 \mathrm{~cm}$.

The assignment of each stump to a decay class in the field was based on a visual assessment of stump morphological characteristics. Stumps were classified according to the fivestage system described by Hunter (1990), based on decay levels with a five-grade scale (Table 2).

Since the stage of decay varies in different parts of the stump, when more than one class of decay was present on the same stump, we used the decay class most widely represented in the cross-section taken at the top of the stump. The cross-sections were wrapped in plastic bags, returned to the laboratory, and stored at $2{ }^{\circ} \mathrm{C}$. Subsamples were cut from the cross-sections: the wood density varied across the samples, so two small block of $1 \mathrm{~cm}^{3}$ were selected in the most and in the least decayed part of the cross-section, in order to obtain two sampling points for each stump. Within the same cross-section, density varied irregularly and randomly, without following a clear trend from pith to bark. For this reason, the 
Table 2 The classification adopted for determining decay stage in stumps according to the five-class system described by Hunter (1990), based on decay levels

\section{Stage Indicators}

1 Stumps with intact bark and all wood sound; intact structure and wood's original colour

2 Bark broken up into patches and partly fallen off; wood still maintains its structural integrity and original colour; the outer layers started to soften because of rot

3 Bark completely absent; all wood structure has started to soften; the soft outer layers disintegrate easily (knife test); the core is still solid and the colour has already started to fade

$4 \quad$ Bark totally absent; texture small and soft; shape oval

5 Wood structure soft and powdery; wood partially covered with moss and vegetation, mixed with the forest soil

location of the two subsamples was defined by using a "knife test", which involves pressing a knife into a stump and classifying the stump according to the penetration, identifying two areas characterized by the most and the least decayed part; we used a simplified approach: $i$, knife penetrates all the way and wood can be broken with the hand and $i i$, knife penetrates $0-5 \mathrm{~mm}$. The values obtained from each samples was an average of these two extreme values.

In order to have a comparison for each species, cores from living trees were sampled and analysed. Ten living trees were cored at the breast height (DBH, $1.30 \mathrm{~m}$ ), for each species. Living trees were located in the same study areas where stumps were selected: the sampling plots were about 2 ha, in each study site. The sampled living trees were characterized by a DBH ranging from 61 to $82 \mathrm{~cm}$ for silver fir and from 65 to $86 \mathrm{~cm}$ for beech. Tree age ranged from 120 to 160 years and from 110 to 150 years for silver fir and beech, respectively. Considering the homogeneity of wood structure and the absence of decomposition for wood in the cores extracted from living trees, only one piece of $1 \mathrm{~cm}^{3}$ for each core was cut and analysed.

Before laboratory analyses (particularly for deadwood) we first removed any moss, fungi, litter and mineral soil particles attached to the surfaces of the samples with a knife and a brush. The samples were then washed after being weighed to $\pm 0.01 \mathrm{~g}$. This washing procedure was conducted for only $5 \mathrm{~min}$ to avoid the leaching of soluble components, after which the samples were dried at $65^{\circ} \mathrm{C}$ until a constant mass was reached (after about $48 \mathrm{~h}$ ) and then weighed.

\subsection{Klason lignin and $\alpha$-cellulose determination}

Part of the two small block obtained from each cross-section were first dried and ground $(<0.1 \mathrm{~mm})$ in a centrifugal mill (Retsch GmbH, Hann, Germany), and soluble phenolics, carbohydrates, and other components were removed by successive extractions. First, water extraction was carried out to separate the supernatant by three incubations with hot water $\left(85^{\circ} \mathrm{C}\right)$ and one with water at ambient temperature, and then the samples were dried $\left(80^{\circ} \mathrm{C}\right)$ overnight. Second, the dried samples were washed three times in ethanol, and then dried $\left(105^{\circ} \mathrm{C}\right)$ overnight. The last step was the extraction with $\mathrm{H}_{2} \mathrm{SO}_{4} 72 \%$. Lignin content was determined from $1 \mathrm{~g}$ of each sample (in two replicates) as the total amount of the insoluble part (Klason lignin) (Dence and Lin 1992) and the soluble part (acid soluble lignin). The Klason lignin was the material remaining at the end of this process. Standard procedures were used for extracting $\alpha$-cellulose (Boettger et al. 2007). Small amounts of the remaining wood derived from the two small blocks $(20-50 \mathrm{mg})$ were washed with $1 \% \mathrm{NaClO}_{2}$ solution at $70{ }^{\circ} \mathrm{C}$ for $30 \mathrm{~h}$, and then transferred into a $17 \% \mathrm{NaOH}$ solution at $25{ }^{\circ} \mathrm{C}$ for $45 \mathrm{~min}$. In order to neutralize $\mathrm{NaOH}$ from the previous steps, the samples were rinsed with $1 \% \mathrm{HCl}$ solution (three times in $5 \mathrm{~min}$ ). After that, $\mathrm{HCl}$ was replaced by hot deionised water. The samples were then dried at $50{ }^{\circ} \mathrm{C}$ in oven for $72 \mathrm{~h}$ and the dry weights measured. The cellulose content was estimated as the ratio between the weight of the cellulose and the dry weight of the original sample.

\subsection{Carbon and nitrogen determination}

In order to test whether there was a change in the $\mathrm{C} / \mathrm{N}$ ratio with increased decomposition, samples from the same area of the disc, for both species were analysed for nitrogen and carbon content. Samples from stumps corresponding to all the five decay classes were considered.

Afterwards, the wood samples were dried to constant weight at $65^{\circ} \mathrm{C}$ (about $48 \mathrm{~h}$ ) and ground with a vibratory mill (0.25 mm; Retsch GmbH, Hann, Germany). Finally, the C/N ratio of all the samples was measured with a $\mathrm{C}+\mathrm{N}$ analyser (NC 2500, CE instruments Thermoquest, Milano, Italy).

\subsection{Years since death, decay classes and biochemical processes}

In a previous study on the same samples, dendrochronological methods were used in order to determine the years since death for the decay classes 1,2 and 3 (for details, see Lombardi et al. 2008). For beech, class 1 died from 2002 to 1977 , class 2 died from 1996 to 1959 and class 3 died from 1994 to 1947; whereas for silver fir, class 1 died from 2002 to 1976, class 2 died from 1998 to 1962 and class 3 died from 1987 to 1951 . It was not possible to estimate the age of death for decay classes 4 and 5 , since the samples were too decayed to use dendrochronological techniques. The years since death suggested a stochastic relationship 
with chemical compounds (data not shown) characterizing the samples analysed. For this reason, results obtained were related to decay classes that better explained the decay progression over time.

\section{Data analysis}

Statistical analyses, using SPSS v.13.0 (SPSS Inc., Chicago, IL, USA), were performed to investigate differences between the relative amounts of chemical compounds among decay classes for each species, between species and for comparison with the chemical composition observed in living trees.

First of all, the distribution of each population (for each species, lignin, cellulose, carbon and nitrogen content of samples) was tested using the KolmogorovSmirnov normality test (Dagnelie 1975). If the result of the normality test was positive (i.e. the distribution of data is normal), parametric comparison methods were adopted. In the present work, this was the case for all the distributions of data analysed. Two sample $t$ tests were used on independent samples, in order to compare the means of each investigated variable. The null hypothesis tested through this method is that there was no differences in lignin, cellulose, carbon or nitrogen content, on one hand between decay classes and living trees within each species and, on the other hand, for each decay class and living trees among species. Results of statistical comparisons were finally adjusted using SPSS, depending on the result of Levene's test for the equality of variances.

\section{Results}

\subsection{Klason lignin}

Patterns of distribution of Klason lignin and $\alpha$-cellulose for all decay classes in silver fir and beech stumps are shown in Fig. 1. Values are presented as a percentage of the total dry mass of each sample. Lignin content in silver fir was
Fig. 1 Klason lignin amounts according to decay classes in silver fir (dark lines) and in beech (pale lines), represented as error bar graph. In the error bar graph, the central circle corresponds to the value of the mean of the distribution while the vertical lines represent the value of two standard deviations in order to provide a measure of dispersion around the mean. In the lower part, the table reports the significant differences between decay classes for each species and between species among the same classes $(* p<0.05 ; * * p<$ 0.01 ; circle non-significant)

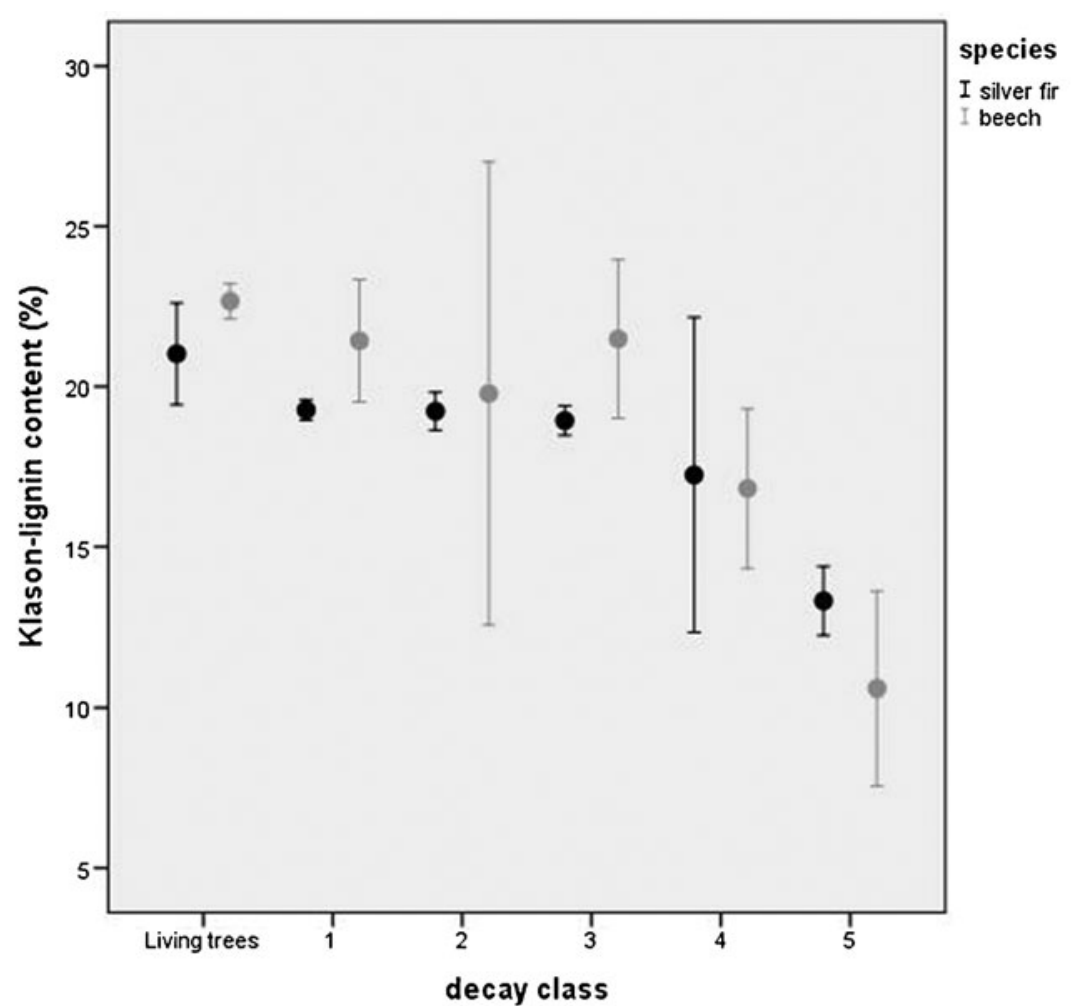

\begin{tabular}{|c|c|c|c|c|c|c|c|c|c|c|c|c|}
\hline & AA & FS & AA & FS & AA & FS & AA & FS & AA & FS & $A A$ & FS \\
\hline & \multicolumn{2}{|c|}{ Living trees } & \multicolumn{2}{|c|}{ Class 1} & \multicolumn{2}{|c|}{ Class 2} & \multicolumn{2}{|c|}{ Class 3} & \multicolumn{2}{|c|}{ Class 4} & \multicolumn{2}{|c|}{ Class 5} \\
\hline Living trees & - & - & & & & & & & & & & \\
\hline Class 1 & $\star$ & o & - & - & & & & & & & & \\
\hline Class 2 & $\star \star$ & o & 0 & 0 & - & - & & & & & & \\
\hline Class 3 & ** & 0 & o & 0 & o & o & - & - & & & & \\
\hline Class 4 & $\star$ & $\star$ & 0 & ** & o & o & o & $\star$ & - & - & & \\
\hline \multirow[t]{2}{*}{ Class 5} & $\star \star \star$ & $\star \star$ & $* *$ & $\star \star \star$ & $\star *$ & $\star \star$ & * & $\star \star$ & ** & $\star \star$ & - & - \\
\hline & \multicolumn{2}{|c|}{ o } & \multicolumn{2}{|c|}{ * } & \multicolumn{2}{|c|}{ o } & \multicolumn{2}{|c|}{0} & \multicolumn{2}{|c|}{0} & \multicolumn{2}{|c|}{ * } \\
\hline
\end{tabular}


significantly higher in living trees than all the decay classes (more than $20 \%$ ) and was significantly lower only in decay class 5, while remaining stable from decay class 1 to decay class 4 (approximately $17 \%$ ). Beech trees had the same amount of lignin as in living trees and decay classes 1,2 and 3 (around $21 \%$ ). In classes 4 and 5 the lignin amount was reduced but was only significantly lower in decay class 5 $(10 \%)$.

Comparing the decay processes between the two species studied, lignin in decay class 1 was significantly higher in beech than in silver fir, while it was lower in beech than in silver fir in decay classes 3, 4 and 5. No other averaged values differed statistically.

Moreover, Klason lignin amounts in beech are more variable than in silver fir, both in living trees and stumps across decay classes. Finally, living trees did not reveal significant differences in Klason lignin amount.

\section{$4.2 \alpha$-Cellulose content}

Trends in Fig. 2 describe $\alpha$-cellulose amounts for all decay classes, as a percentage of total dry mass. We found a decrease from $44 \%$ (decay class 1 ) to $12 \%$ (decay class
5), for silver fir, and from $39 \%$ (decay class 1 ) to $5 \%$ (decay class 5), for beech. Unfortunately, cellulose data for living trees are not available. Therefore, pure cellulose decreased with decay classes, even if the rate of the decay was not regular from the least to the most decayed samples. Its concentration was not significantly different between classes 1 and 2, for silver fir; in beech samples, cellulose amounts were not significantly different among classes 1 , 2 and 3. Finally, the most decayed samples (classes 4 and 5) were characterized by significant lower amounts of pure cellulose than other classes. Cellulose content was similar in classes 1 and 3, while being higher in beech than in silver fir in classes 2, 4 and 5 . The standard deviation, particularly in class 3 , revealed high variability between samples.

Pure cellulose was higher than Klason lignin in decay classes 1, 2 and 3, in both species. With the processes of decay, an inversion of lignin and cellulose percentage occurred in beech samples, particularly in the transition from class 4 to class 5: the most decayed samples being richer in lignin than in $\alpha$-cellulose. Silver fir samples were always richer in lignin than cellulose, with the exception of decay class 5 , in which the percentage of these chemical compounds was similar, around $12 \%$.
Fig. $2 \alpha$-Cellulose amounts according to decay classes in silver fir (dark lines) and in beech (pale lines). In the lower part, the table reports the significant differences between decay classes for each species and between species among the same classes $(* p<0.05 ; * * p<$ 0.01 ; circle non-significant)

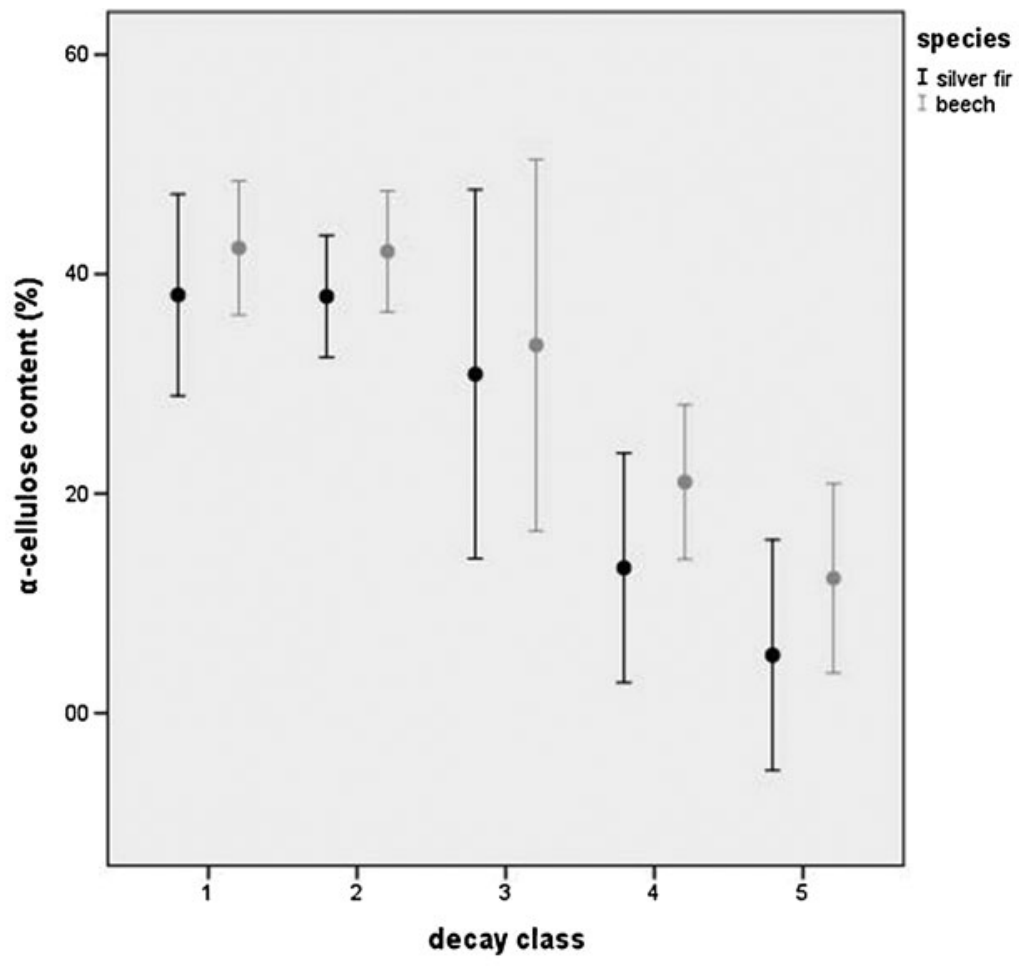

\begin{tabular}{|c|c|c|c|c|c|c|c|c|c|c|}
\hline & AA & FS & AA & FS & AA & FS & AA & FS & AA & FS \\
\hline & \multicolumn{2}{|c|}{ Class 1} & \multicolumn{2}{|c|}{ Class 2} & \multicolumn{2}{|c|}{ Class 3} & \multicolumn{2}{|c|}{ Class 4} & \multicolumn{2}{|c|}{ Class 5} \\
\hline Class 1 & - & - & & & & & & & & \\
\hline Class 2 & 0 & 0 & - & - & & & & & & \\
\hline Class 3 & * & 0 & * & 0 & - & - & & & & \\
\hline Class 4 & ** & ** & $\star \star$ & ** & * & ** & - & - & & \\
\hline \multirow[t]{2}{*}{ Class 5} & ** & ** & ** & ** & ** & ** & ** & * & - & - \\
\hline & \multicolumn{2}{|c|}{0} & & & \multicolumn{2}{|c|}{0} & \multicolumn{2}{|c|}{$\star$} & \multicolumn{2}{|c|}{ * } \\
\hline
\end{tabular}




\subsection{Carbon and nitrogen concentrations}

Carbon and nitrogen contents were calculated as percentage of the total dry mass basis, in relation to decay classes. For silver fir, distribution patterns of carbon showed lower concentration in deadwood than in living trees (Fig. 3). Stumps in classes 1 and 2 showed similar amounts of carbon, while carbon slightly increased for decay stages 3 to 5 . Values were invariably high, lowering by only $2 \%$ from living trees to the most decayed class of decomposition, although class 5 was characterized by high variability between samples. For beech, samples in class 1 showed lower amount of carbon (less than $45 \%$ ) in comparison with the other decay stages and with living trees. For the remaining decay classes the carbon amount was almost constant throughout the decay process (Fig. 3), with values not dissimilar to those recorded for living trees. Also for beech, class 5 revealed high variability between samples.

Living silver fir trees were characterized by significantly higher carbon content in comparison with beech, but when comparing the same decay classes, the two species studied revealed similar percentages of carbon throughout the processes of wood decay.

Similarly to carbon, there were no significant differences between the two species for nitrogen content, except for stumps in class 1 where the nitrogen content was higher in beech than in silver fir. In contrast to the carbon content, the living trees were characterized by similar amounts of nitrogen. However, the main result showed in Fig. 4 was the marked increase in nitrogen content from living trees to decay classes 1, 2 and 3, with higher values recorded in the last two decay classes in both species; values increased approximately from 0.15 to $0.80 \%$.

Overall, silver fir stumps showed a slight decrease in nitrogen content from living trees to classes 1 and 2, followed by a small increase to class 3 and, finally, by a large increase to classes 4 and 5 . These last two classes did not differ statistically from each other.

Beech samples had similar percentage of nitrogen from living trees to class 3 . Then, values increased strongly from $0.15 \%$ to more than $0.90 \%$ in class 5 . The most decomposed classes ( 4 and 5) differed statistically from each other,
Fig. 3 Carbon content according to decay classes in silver fir (dark lines) and in beech (pale lines). In the lower part, the table reports the significant differences between decay classes for each species and between species among the same classes $\left({ }^{*} p<0.05 ; * * p<\right.$ 0.01 ; circle non-significant)

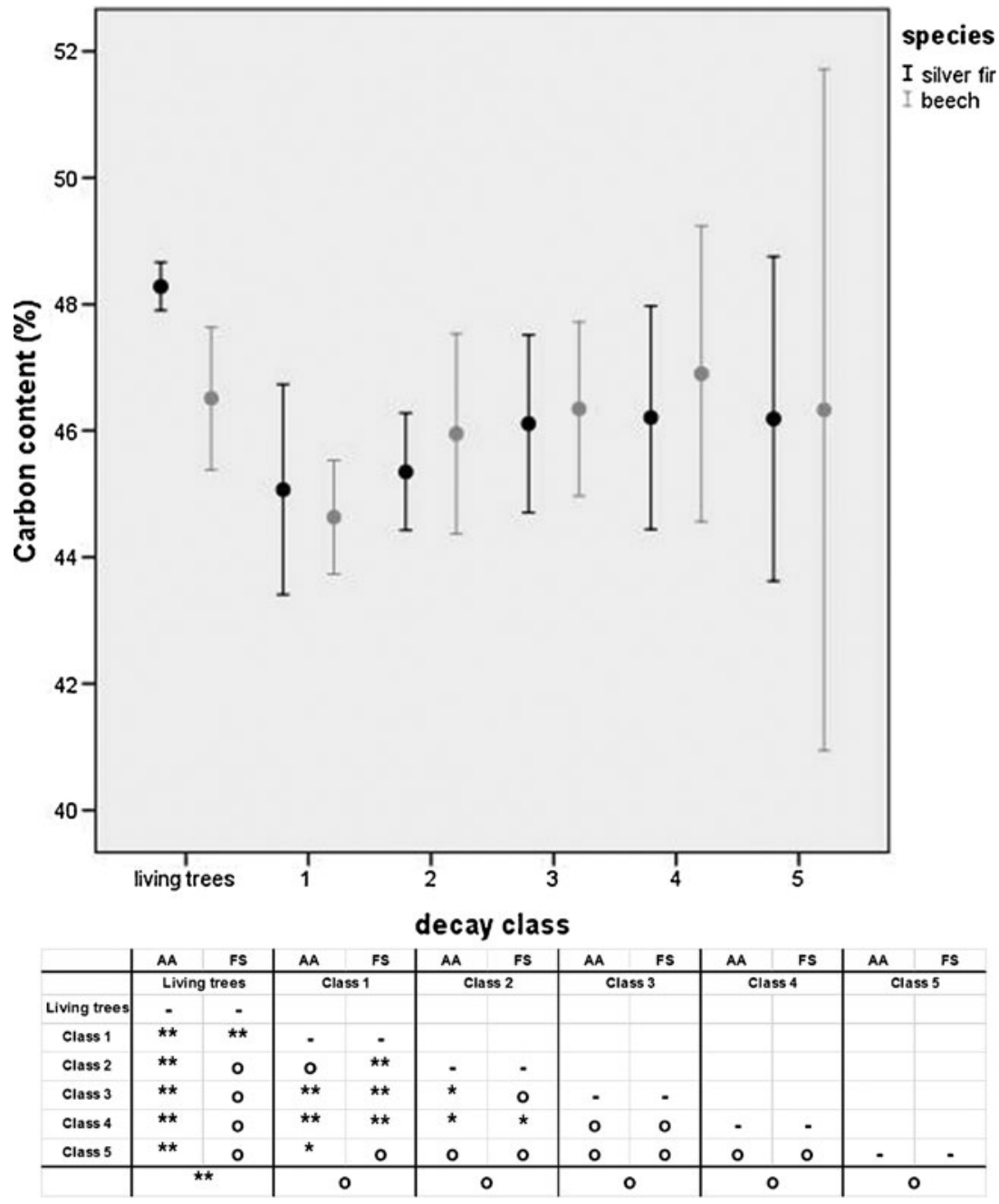


Fig. 4 Nitrogen content according to decay classes in silver fir (dark lines) and in beech (pale lines). In the lower part, the table reports the significant differences between decay classes for each species and between species among the same classes $(* p<0.05 ; * * p$ $<0.01$; circle non-significant)

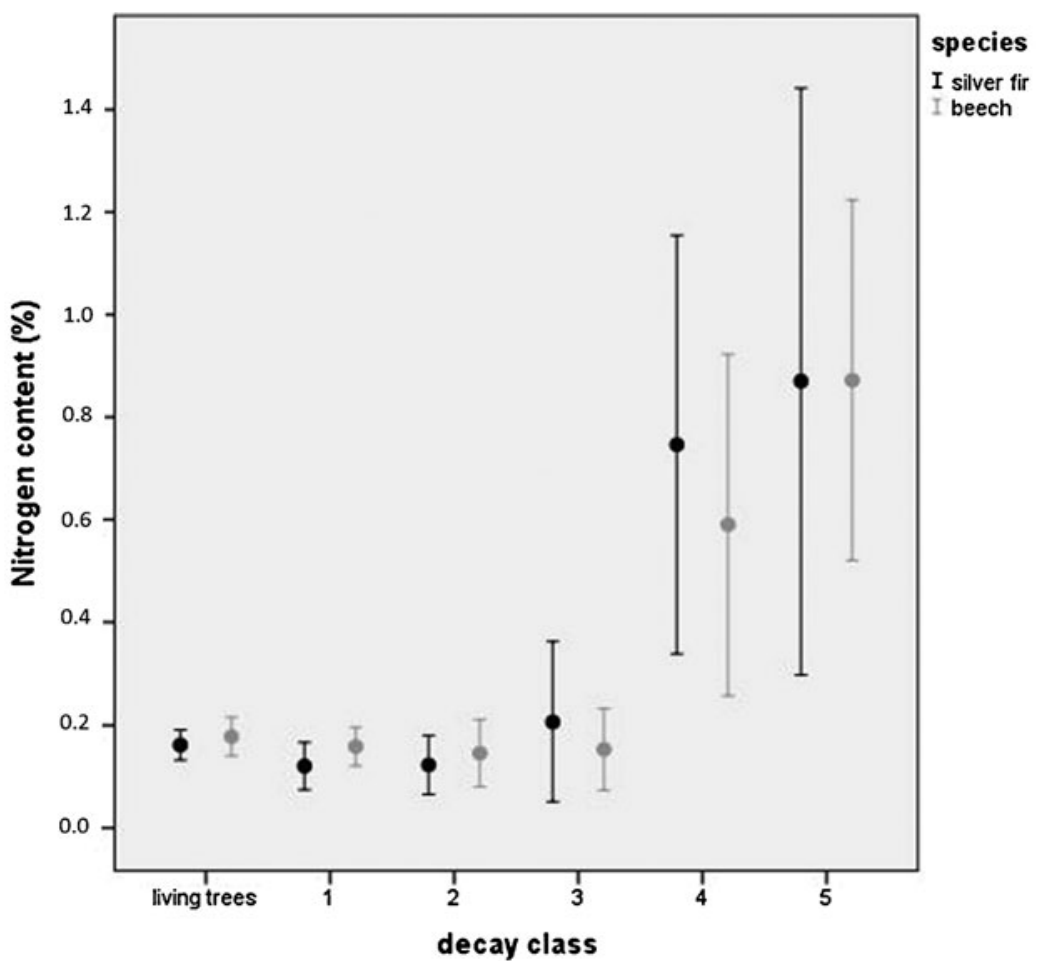

\begin{tabular}{|c|c|c|c|c|c|c|c|c|c|c|c|c|}
\hline & AA & FS & AA & FS & AA & FS & AA & FS & AA & FS & AA & FS \\
\hline & \multicolumn{2}{|c|}{ Living trees } & \multicolumn{2}{|c|}{ Class 1} & \multicolumn{2}{|c|}{ Class 2} & \multicolumn{2}{|c|}{ Class 3} & \multicolumn{2}{|c|}{ Class 4} & \multicolumn{2}{|c|}{ Class 5} \\
\hline Living trees & - & - & & & & & & & & & & \\
\hline Class 1 & $\star \star$ & 0 & - & - & & & & & & & & \\
\hline Class 2 & $\star \star \star$ & $\star$ & 0 & 0 & - & - & & & & & & \\
\hline Class 3 & 0 & 0 & $\star \star$ & 0 & $\star \star \star$ & 0 & - & - & & & & \\
\hline Class 4 & $\star \star$ & $\star \star$ & $\star \star$ & $\star \star \star$ & $\star \star$ & $\star \star$ & $\star \star$ & $\star \star$ & - & - & & \\
\hline \multirow[t]{2}{*}{ Class 5} & $\star \star \star$ & $\star \star$ & 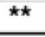 & $\star \star$ & $\star \star \star$ & $\star \star$ & $\star \star \star$ & ** & 0 & ** & - & - \\
\hline & \multicolumn{2}{|c|}{ o } & \multicolumn{2}{|c|}{$\star \star$} & \multicolumn{2}{|c|}{0} & \multicolumn{2}{|c|}{0} & \multicolumn{2}{|c|}{0} & \multicolumn{2}{|c|}{0} \\
\hline
\end{tabular}

with higher values in class 5 . Finally, the samples revealed a high variability between samples in class 5 .

\section{Discussion}

Chemical compounds were reported on a total dry mass basis, without considering the relative amount of each compound. Therefore, because of the different methodological approach, the relative increase of lignin and cellulose, as generally observed in other studies (Bütler et al. 2007; Hedges et al. 1985), was not found in the present experiment. In both species, lignin persisted longer than cellulose. One explanation could be related to the inhibitory effects induced by low moisture and consequent anaerobiosis inside the wood, restricting the oxidative decomposition of lignin by fungi (Preston et al. 1990). Another hypothesis could be that the low-incoming radiation levels on the forest floor reduce the photodegradation of lignin. Lignin content was similar in living trees and decay classes 1 to 4 in silver fir, whereas in beech, lignin content started decreasing from decay class 3 , onwards.

In the Apennines, Rutigliano et al. (1996) also demonstrated that lignin degradation was slower in silver fir than in beech, with lignin losses of $60-67 \%$ and $73-87 \%$ of initial amount, respectively; differences in decay rates between beech and silver fir litter were always consistent with differences in lignin concentration. It is evident that in the early phase of decay, lignin decomposed faster in beech than in silver fir, while in the late stage of decay, lignin decomposition tended to be higher in silver fir than in beech. In gymnosperms, lignin would be slowly degraded due to the resistance to decay of guaiacyl-based lignin, while in angiosperms, syringyl-based lignin would tend to be more easily decomposed (Ganjegunte et al. 2004). The slower decay of lignin compared to cellulose suggested that lignin might be a more constant source of carbon so that it provides a stable background source of organic carbon to the forest soil. Klason lignin amounts in beech appeared more variable than in silver fir, both in living trees and stumps across decay classes. This might affect processes of wood decay and formation of humic substances since various fungi act differently on the cellulose and lignin of wood. Melillo et al. (1983) found that woody debris of deciduous species decomposed at higher rates than conifer species. Unfortunately, there is paucity of information on decomposition processes and related communities of decomposers in Mediterranean mountain forests. 
Cellulose decayed faster than lignin in the last three decay classes and an inversion of lignin and cellulose percentages particularly in the transition from class 4 to class 5, was observed. Class 5 was characterized by higher variability of data between samples. Considering the definition of class 5 (soft and powdered wood structure, and wood partially covered with moss/vegetation and mixed with the forest soil), it might be that the larger variability was related to the intense interaction between wood and soil chemical compounds. Micro-environmental characteristics, as well as the likely greater age variation of wood samples would, therefore, explain the extreme variability of data.

Cellulose content was not statistically different between species in the first stages of decay progression, while differences in cellulose levels were observed in the most decayed samples (decay classes 4 and 5), wherein it was higher in beech than in silver fir. Cellulose is easily decomposed by decomposing organisms, particularly in coniferous trees that are characterized by a relatively simple wood structure (Laiho and Prescott 2004; Lambert et al. 1980). Indeed, substrate quality and local environment (temperature, precipitation, aeration and decomposers) are key factors influencing rates of decay (Zhou et al. 2007). Wood chemistry, e.g. content of carbon, nitrogen and lignin, and other species-specific traits can have significant influence on the course of decomposition (Harmon et al. 1986). Higher carbohydrate concentration is known to enhance decomposition rates (Preston 1992). In contrast, the presence of compounds such as tannins and lignin, which are capable of restricting microbial colonization, can inhibit wood decomposition (Baldock et al. 1997). Preferential degradation of carbohydrates (by brown rot fungi) with a concomitant increase in the concentration of aromatic compounds in deadwood has been also reported in many studies (Preston et al. 1990; Baldock et al. 1997). On the other hand, in a global data set compiled in a review on the decomposition trends on deadwood, no relationships between the lignin and cellulose content were observed among decay classes (Mackensen et al. 2003), demonstrating the extreme variability of data sets in relation to specific study areas.

The carbon fraction of stumps ranged from 44 to $48 \%$ in both species. The value observed was smaller than usually reported for logs of temperate zones. Lambert et al. (1980) also reported a steady carbon concentration, of 48 to $52 \%$ in balsam fir (Abies balsamea (L.) Mill.), boles of varying stages of decay. Laiho and Prescott (1999) report a carbon fraction of $50 \%$ in Engelmann spruce (Picea engelmannii Parry ex Engelm.) logs after 14 years of decomposition. In this study, the carbon fraction of deadwood was $2 \%$ lower than that of fresh stem wood. Moreover, from decay stage 3 to 5 the carbon concentration slightly increased. It may be hypothesized that the presence of cerambycid frass and fungi in the xylem enhanced carbon concentration in the heartwood, as showed in previous studies (Torres 1994). The constant carbon values, compared with the reduction of original water-soluble carbohydrates, demonstrated how carbohydrates tend to be disaggregated into simple aromatic compounds (therefore not extracted as Klason lignin or cellulose). Consequently, deadwood was still characterized by the occurrence of decay-resistant materials allowing carbon to persist, even if in a relatively changed form, for several decades or centuries (Lombardi et al. 2011). Nitrogen concentration of decaying wood is of particular interest, owing to its role in the function of terrestrial ecosystems, but also because it can affect the rate of decay (Cowling and Merril 1966). The nitrogen concentration remained quite constant as decay progressed (from living trees to class 3 ) until the advanced decay stages, at which point nitrogen levels increased sharply and significantly, with the highest values recorded for the last two decay classes, indicating that decayed woody debris may be an important source of nitrogen over a long time scale. Deadwood may act as a constant source of nitrogen rather than providing a sudden increase in the availability of nutrients, as in the case of leaf and needle litter. This would be important for the biogeochemistry of these Mediterranean mountain forests and for buffering changes in the concentrations of soil nitrogen concentration. These findings are consistent with results already observed in other environments (Ganjegunte et al. 2004; Laiho and Prescott 2004; Lambert et al. 1980; Saunders et al. 2011), even though the observation has not always been statistically significant across species. The most plausible explanation of this increase could be related to the fact that as the material became increasingly fragmented, it was also more accessible to microflora. The fungal retention of the original nitrogen as well as translocation of new nitrogen into the decomposing stumps from litter fall and crown wash increase, and from fungal transfer from the surrounding forest floor or soil (Harmon et al. 1994). In addition, fixation of nitrogen by bacteria may also add nitrogen in the most decomposed stumps (Graham and Cromack 1982). The relative importance of these mechanisms was not identified in the present study, but together these mechanisms may be an efficient mechanism in these forests.

Nitrogen concentrations found in our study were low in comparison with those observed in other studies (Krankina et al. 1999). Nevertheless, we studied debarked wood, whereas in Krankina et al. (1999) and studies described therein reported chemical analyses of samples containing bark, which contains more nutrients than wood. The starting nutrient concentration values were consequently rather higher in the work of Krankina et al. (1999) compared to our debarked samples. Samples in class 5 revealed the highest variability in nitrogen content amongst samples, as also observed for lignin, cellulose and carbon contents, which 
might be most probably ascribed to the bigger age variation, but also to the high interrelation with soil characteristics.

Our study was limited to a small study area, characterized by specific climatic conditions and forest structures. Nevertheless, results are similar to those obtained in more comprehensive studies (Angers et al. 2010), and could be used to understand the role of deadwood in nutrient cycling in Mediterranean forest ecosystems. Decomposition processes in the investigated montane-Mediterranean forests were definitely faster than in colder climates of northern Europe. In a previous study conducted in the same area and on the same samples (Lombardi et al. 2008), it was observed how the correlation between decay classes and the number of years since tree death of trees was not strong and the age variation of stumps within decay classes was rather high. Microclimate conditions on the forest floor may influence the decay progression. Water availability, micro-topography and incoming radiation are factors that influence the high variability of decomposition patterns after tree death. Moreover, decay is also influenced by the causes of tree death, which might imply that the investigated trees had suffered from progressive weakening of the bole through fungal decomposition while still alive, in contrast to trees suffering sudden death such as though stem breakage during a storm.

Decay classes selected by visual identification may still be useful to distinguish and observe the decay progression in relation to wood characteristics, such as hardness, resistance and penetrability, and decay classes may reflect the relative abundance of chemical compounds that define physical properties of the wood, in terms of wood density and wood resistance (Larjavaara and Muller-Landa 2010). Easily determined decay classes can assist in the determination of carbon and nitrogen levels within woody litter in Mediterranean mountain forests, thus contributing to estimates of the carbon and nitrogen cycling in such ecosystems.

We recommend establishing long-term monitoring in Mediterranean forests that will allow investigation of the different factors that may influence deadwood decomposition, such as edaphic and climatic conditions, as well as monitoring the release of nutrients and forest biogeochemistry. A better knowledge of the functional roles and dynamics of the deadwood would help us to improve our understanding of terrestrial nutrient cycles and carbon sequestration. In order to better understand the processes influencing decay rates, since decay classes may also be related to the presence of saproxylic organisms, the role of soil fauna (earthworms and microarthropods), soil microorganisms, fungi and their biological processes need to be investigated in Mediterranean mountainous forest ecosystems. For this reason, analyses on saproxylic colonization throughout the wood decay process are in progress in the same study sites, with the purpose of understanding the relationships between patterns of decay and the presence of saproxylics.
Acknowledgements This research was funded by the European Community in the context of the LIFE+Environment Policy and Governance 2009 project "ManFor C.BD: Managing forests for multiple purposes: carbon, biodiversity and socio-economic wellbeing".

The study sites belong to the European Community (EU) network Natura 2000, which aims to preserve biodiversity within the EU territory. We thank "Comunità Montana Alto Molise" (Agnone, Is) and "Ufficio Territoriale per la Biodiversità" (Isernia) for technical support. The authors are grateful to Dr. M. Dobbertin for his precious suggestion in data analyses. Finally, thanks also to M. Florio for his contribution in the lab activities.

\section{References}

Aakala T (2010) Coarse woody debris in late-successional Picea abies forests in northern Europe: variability in quantities and models of decay class dynamics. For Ecol Manage 260:770-779

Angers VA, Drapeau P, Bergeron Y (2010) Snag degradation pathways of four North American boreal tree species. For Ecol Manage 259:246-256

Baldock JA, Sewell T, Hatcher PG (1997) Decomposition induced changes in the chemical structure of fallen red pine, white spruce and Tamarack logs. In: Cadisch G, Giller KE (eds) Driven by nature: plant litter quality and decomposition. CAB International, Wallingford

Boettger T, Haupt M, Knöller K, Weise SM, Waterhouse JS, Rinne KT, Loader NJ, Sonninen E, Jungner H, Masson-Delmotte V, Stievenard M, Guillemin MT, Pierre M, Pazdur A, Leuenberger M, Filot M (2007) Wood cellulose preparation methods and mass spectrometric analyses of $\delta^{13} \mathrm{C}, \delta^{18} \mathrm{O}$, and nonexchangeable $\delta^{2} \mathrm{H}$ values in cellulose, sugar, and starch: an interlaboratory comparison. Anal Chem 79:4603-4612

Bretz Guby NA, Dobbertin M (1996) Quantitative estimates of coarse woody debris and standing dead trees in selected Swiss forests. Global Ecol Biogeogr 5:327-341

Bütler R, Patty L, Le Bayon RC, Guenat C, Schlaepfe R (2007) Log decay of Picea abies in the Swiss Jura Mountains of Central Europe. For Ecol Manage 242:791-799

Cherubini P, Fontana G, Rigling D, Dobbertin M, Brang P, Innes JL (2002) Tree-life history prior to death: two fungal root pathogens affect tree-ring growth differently. J Ecol 90:839-850

Cowling EB, Merril W (1966) Nitrogen in wood and its role in wood deterioration. Can J Bot 44:1539-1554

Dagnelie P (1975) Théorie et méthodes statistiques, Volume 2. Gembloux, Belgium: Les Presses Agronomiques De Gembloux, A.S.B.L., p 463

Daniels LD, Dobry J, Klinka K, Feller MC (1997) Determining year of death of logs and snags of Thuja plicata in southwestern coastal British Columbia. Can J For Res 27:1132-1141

Dence CW, Lin SY (1992) Introduction. In: Lin SY, Dence CW (eds) Methods in lignin chemistry. Springer, Heidelberg, pp 1-19

Ganjegunte LM, Condron PW, Clinton MR, Mahieu N (2004) Decomposition and nutrient release from radiata pine (Pinus radiata) coarse woody debris. For Ecol Manage 187:197-211

Graham RL, Cromack K Jr (1982) Mass, nutrient content, and decay rate of dead boles in rain forests of Olympic. Can J For Res 12:511-521

Harmon ME, Franklin JF, Swanson FJ, Sollins P, Gregory SV, Lattin JD, Anderson NH, Cline SP, Aumen NG, Sedell JR, Lienkaemper GW, Cromack K, Cummins KW (1986) Ecology of coarse woody debris in temperate ecosystems. Adv Ecol Res 15:133-302

Harmon ME, Sexton J, Caldwell BA, Carpenter SE (1994) Fungal sporocarp mediated losses of $\mathrm{Ca}, \mathrm{Fe}, \mathrm{K}, \mathrm{Mg}, \mathrm{Mn}, \mathrm{N}, \mathrm{P}$ and $\mathrm{Zn}$ from conifer logs in the early stages of decomposition. Can J For Res 24:1883-1893 
Hedges JI, Cowie GL, Ertel JR, Barbour RJ, Hatcher PG (1985) Degradation of carbohydrates and lignins in buried woods. Geochim Cosmochim Acta 49:701-711

Hunter ML (1990) Wildlife, forests, and forestry: principles of managing forests for biological diversity. Englewood Cliffs, USA

Krankina ON, Harmon ME, Griazkin AV (1999) Nutrient stores and dynamics of woody detritus in a boreal forest: modelling potential implications at the stand level. Can J For Res 29:20-32

Laiho R, Prescott CE (1999) The contribution of coarse woody debris to carbon, nitrogen, and phosphorous cycles in three Rock Mountain coniferous forests. Can J For Res 29:1592-1603

Laiho R, Prescott CE (2004) Decay and nutrient dynamics of coarse woody debris in northern coniferous forests: a synthesis. Can J For Res 34:763-777

Lambert RL, Lang GE, Reiners WA (1980) Loss of mass and chemical change in decaying boles of a subalpine balsam fir forest. Ecology 61:460-1473

Larjavaara M, Muller-Landa HC (2010) Comparison of decay classification, knife test and two penetrometers for estimating wood density of coarse woody debris. Can J For Res 40:2313-2321

Lassauce A, Paillet Y, Jactel H, Bouget C (2011) Deadwood as a surrogate for forest biodiversity: meta-analysis of correlations between deadwood volume and species richness of saproxylic organisms. Ecol Indic 11:1027-1039

Lombardi F, Cherubini P, Lasserre B, Tognetti R, Marchetti M (2008) Tree rings used to assess time-since-death of deadwood of different decay classes in beech and silver fir forests in the Central Apennines (Molise, Italy). Can J For Res 38:821-833

Lombardi F, Chirici G, Marchetti M, Tognetti R, Lasserre B, Corona P, Barbati A, Ferrari B, Di Paolo S, Giuliarelli D, Mason F, Iovino F, Nicolaci A, Bianchi L, Maltoni A, Travaglini D (2010) Deadwood in forest stands close to old-growthness under Mediterranean conditions in the Italian peninsula. Ital $\mathrm{J}$ For Mount Environ 65:481-504

Lombardi F, Cocozza C, Lasserre B, Tognetti R, Marchetti M (2011) Dendrochronological assessment of time-since-death in the oldgrowth Magellan's beech forest of Navarino Island (Chile). Austral Ecol 36:329-340
Mackensen J, Bauhus J (2003) Density loss and respiration rates in coarse woody debris of Pinus radiata, Eucalyptus regnans and Eucalyptus maculata. Soil Biol Biochem 35:177-186

Mackensen J, Bauhus J, Webber E (2003) Decomposition rates of coarse woody debris - a review with particular emphasis on Australian tree species. Aust J Bot 51:27-37

Melillo JM, Naiman RJ, Aber JD, Eshleman KN (1983) The influence of substrate quality and stream size on wood decomposition dynamics. Oecologia 58:281-285

Muller-Using S, Bartsch N (2009) Decay dynamic of coarse and fine woody debris of a beech (Fagus sylvatica L.) forest in Central Germany. Eur J For Res 128:287-296

Olajuyigbe SO, Tobina B, Gardinera P, Nieuwenhuisa M (2011) Stocks and decay dynamics of above- and belowground coarse woody debris in managed Sitka spruce forests in Ireland. For Ecol Manage 262:1109-1118

Preston CM (1992) The application of NMR to organic matter inputs and processes in forest ecosystems of the Pacific northwest. Sci Tot Environ 113:107-120

Preston CP, Sollins P, Sayer BG (1990) Changes in organic components for fallen logs in old-growth Douglas-fir forests monitored by ${ }^{13} \mathrm{C}$ nuclear magnetic resonance spectroscopy. Can J For Res 20:1382-1391

Richards KR, Stokes C (2004) A review of forest carbon sequestration cost studies: a dozen years of research. Clim Change 63:1-48

Rutigliano FA, Virzo de Santo A, Berg B, Alfani A, Fioretto A (1996) Lignin decomposition in decaying leaves of Fagus sylvatica L. and needles of Abies alba Mill. Soil Biol Biochem 28:101-106

Saunders MR, Fraver S, Wagner RG (2011) Nutrient concentration of down woody debris in mixedwood forests in central Maine, USA. Silva Fenn 45:197-210

Torres JA (1994) Wood decomposition of Cyrilla racemiflora in a tropical montane forest. Biotropica 26:124-140

Wilcke W, Hess T, Bengel C, Homeier J, Valarezo C, Zech W (2005) Coarse woody debris in a montane forest in Ecuador: mass, $\mathrm{C}$ and nutrient stock, and turnover. For Ecol Manage 205:139-147

Zhou L, Dai LM, Gu HY, Zhong L (2007) Review on the decomposition and influence factors of coarse woody debris in forest ecosystem. J For Res 18:48-54 